\title{
Sistema Integral de Verdad, Justicia, Reparación y No Repetición: un acuerdo de justicia ¿restaurativa? ${ }^{* * *}$
}

\section{Integral System of Truth, Reparations, Justice and Non-repetition: Agreement of restorative justice?}

SUMARIO

1. La justicia restaurativa en el acuerdo. 2. Justicia restaurativa: una discusión conceptual. Consideraciones finales. Referencias.

\section{RESUMEN}

El presente escrito presenta un estudio sobre el concepto y la aplicación de la justicia restaurativa. ¿En qué consiste la justicia restaurativa? ¿Cuál es su aplicación concreta y cuáles sus posibles problemas en el contexto de las negociaciones del fin del conflicto armado en Colombia? Para este desarrollo nos enfocamos en un caso preciso, a saber, el Sistema Integral de Verdad, Justicia, Reparación y No Repetición contenido en el acuerdo entre el Gobierno colombiano y la guerrilla de las FARC. Este acuerdo incluye un pacto sobre justicia restaurativa que será expuesto en una primera parte. Pese

* Investigadora brasilera. Bacharel (2007) em Ciências Sociais pela Universidade Federal de São Carlos, é mestre (2010) pelo Programa de Pós-Graduação em Sociologia, doutora (2015) pelo Programa de Pós-Graduação em Sociologia da Universidade de São Paulo, com período sanduíche no Departamento de Criminologia da Universidade de Ottawa. Doctoranda del Departamento de Sociologia de la usP junto ao Projeto Temático FAPESP "A gestão do conflito na produção da cidade contemporânea: a experiência paulista" sob supervisão do prof. Luís Antônio Francisco de Souza. Contacto: jutonche@gmail.com

*** Abogado de la Universidad Externado de Colombia con posgrado en Derechos Humanos y Derecho Internacional Humanitario. Candidato a $\mathrm{PhD}$ de la Universidad de Ottawa, en el programa de Criminología, y candidato a doctor de la Universidad del País Vasco, en el programa de Sociología Jurídica, con una investigación sobre impunidad, criminalidad de Estado y racionalidad penal moderna. Máster en Sociología Jurídica del Instituto Internacional de Sociología Jurídica. Docente investigador en la Facultad de Derecho de la Universidad Externado de Colombia (Bogotá, Colombia). Contacto: camiloeduh@hotmail.com

**** Este artículo es producto de una investigación conjunta de los autores y hará parte de una publicación de un artículo extenso sobre el tema en portugués.

Recibido el 25 de septiembre de 2016, aprobado el 1. ${ }^{\circ}$ de marzo de 2017.

Para citar el artículo: TonCHE, J. y UMAÑA, C. E. Sistema integral de verdad, justicia, reparación y no repetición. Un acuerdo de justica ¿restaurativa? Derecho del Estado . $^{\circ} 38$, Universidad Externado de Colombia, enero-junio de 2017, pp. 223-241. Dor: https://doi.org/10.18601/01229893.n38.09 
a no haber sido refrendado por la población colombiana, este acuerdo traza la hoja de ruta de un próximo acuerdo en el anhelo de poner fin al conflicto armado que afecta a Colombia. Como tal, es un documento válido y relevante para este estudio, sobre todo porque estas medidas han sido objeto de cuestionamiento por algunos de los voceros de quienes están en contra de la refrendación del acuerdo.

El acuerdo será evaluado y valorado conforme con una elucidación conceptual sobre la justicia restaurativa que haremos en la segunda parte de este escrito. Finalmente, ofreceremos unas conclusiones orientadas a entender de una mejor manera la conceptualización y presencia empírica de la justicia restaurativa en el mundo contemporáneo, y específicamente los problemas, ventajas y cuestionamientos en el contexto del intento de salida del conflicto armado en Colombia.

PALABRAS CLAVE

Acuerdo de paz; Colombia; FARC; justicia restaurativa; justicia penal.

ABSTRACT

This paper presents a study on the concept and implementation of restorative justice. What is restorative justice? How can we characterize its implementation? What are possible problems in the context of negotiations for the end of the armed conflict in Colombia? This article analyzes provisions of restorative justice that can be found in the Integral System of Truth, Justice, Reparation and Non-Repetition (SIVJRR): a system of dispositions that emerged from the peace negotiation between the government of Colombia and the FARC (Revolutionary Armed Forces of Colombia), with the aim of ending the internal armed conflict. Given the complexity of the agreement and its context, a model of restorative justice has emerged from the agreements, as a possibility to address the situation in a more humane way, with the goal of restoring social relations affected by conflict. Our conclusions show the problems and complexities of the use of restorative justice. However, this agreement may be understood as a step forward showing the willingness on both sides to move away from the usual punitive model of conflict response, the logic of the criminal justice system based on retributivism and punishment still predominates.

KEYWORDS

Peace agreement; Colombia; FARC; restorative justice; criminal justice. 
RESUMO

Este artigo se propõe a fazer uma análise das provisões de justiça restaurativa que podem ser encontradas no Sistema Integral de Verdade, Justiça, Reparação e não Repetição (SIVJRR): um sistema de disposições que emergiu a partir de iniciativas de aproximações entre o governo da Colômbia e as FARC (Forças Armadas Revolucionárias da Colômbia) com o objetivo de dar fim ao conflito armado interno. Dada a complexidade do contexto que o acordo deve atender, um modelo alternativo da justiça restaurativa emergiu como possibilidade de abordar a situação de uma forma mais humana, com foco na restauração das relações sociais afetadas pelo conflito. Entretanto, as conclusões do artigo vão na direção de apontar como embora o recurso à justiça restaurativa possa ser entendido como um avanço, na medida em que parece evidenciar uma vontade de ambas as partes do acordo em se afastarem do modelo punitivo usual de resposta aos conflitos, a lógica do sistema de justiça criminal, que se baseia sobre o retributivismo e punição, ainda predomina.

PALAVRAS CHAVE

Acordo de paz; Colômbia; FARC; justiça restaurativa; justiça criminal.

\section{LA JUSTICIA RESTAURATIVA EN EL ACUERDO}

En un contexto de conflicto armado interno, en Colombia se han presentado diferentes negociaciones e iniciativas de pacificación con diferentes movimientos guerrilleros (Umaña, 2016). Entre ellas, la más reciente es la mesa de negociaciones instalada los días 17 y 18 de octubre de 2012 en La Habana entre el Gobierno colombiano y la guerrilla de las Fuerzas Armadas Revolucionarias de Colombia (en adelante, FARC) (Mesa de Conversaciones, 2012b).

A raíz de estos acercamientos y con la intención mutua de poner fin al conflicto, las partes acordaron iniciar conversaciones directas e ininterrumpidas para construir un acuerdo que pudiera contribuir a la construcción de una paz duradera y estable. Con miras a trabajar sobre un acuerdo, las partes acordaron una agenda de negociación denominada "Acuerdo General para la terminación del conflicto y la construcción de una paz estable y duradera". En dicha agenda, uno de los puntos de negociación establecidos buscaba el reconocimiento, reparación y satisfacción de las víctimas, así como el esclarecimiento de la verdad, la garantía de no repetición y el reconocimiento de responsabilidad por parte de los victimarios (Mesa de Conversaciones, 2014a).

Conforme con esto, el 15 de diciembre de 2015 se llegó a un acuerdo publicado mediante el Comunicado Conjunto $n .{ }^{\circ} 64$, documento que hace parte del Acuerdo Final para la Terminación del Conflicto y la Construcción de una Paz Estable y Duradera, suscrito el 26 de septiembre de 2016 en la ciudad 
de Cartagena en presencia de altos mandatarios del mundo y del Secretario General de las Naciones Unidas. Este acuerdo fue sometido a la refrendación del pueblo colombiano en un plebiscito celebrado el 2 de octubre de 2016. En dicha consulta se preguntó al electorado: “ ¿Apoya usted el Acuerdo final para la terminación del conflicto y la construcción de una paz estable y duradera?". De las 34.899.000 personas habilitadas para sufragar, tan sólo votaron 13.066 .047 (equivalente al $37,43 \%$ de las habilitadas). Con una abstención del $62,57 \%$, un 49,78\% votó "Sî" (6.377.482 personas), mientras que un 50,21\% votó "No" (6.431.376 personas).

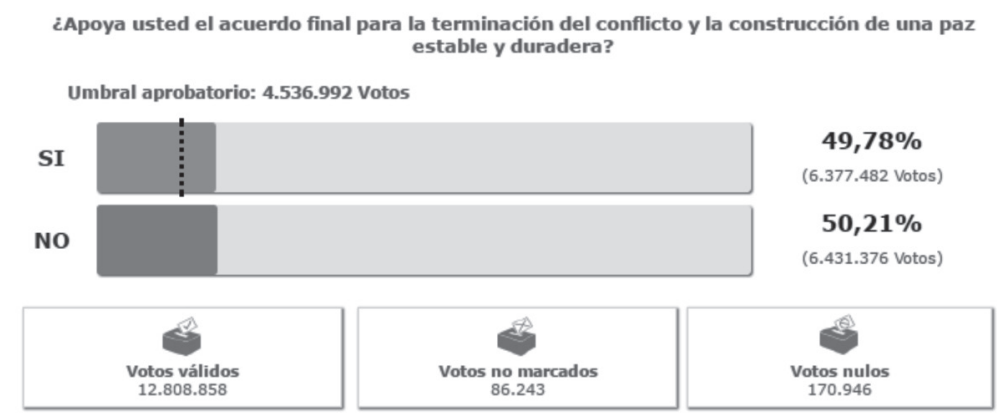

Fuente: Registraduría Nacional del Estado Civil, disponible en: [http://plebiscito.registraduria.gov.co/99PL/ DPLZZZZZZZZZZZZZZZZZ_L1.htm].

Con la victoria electoral del "No" se presentó una intensa discusión social sobre la posibilidad de modificar los acuerdos para llegar a una solución del conflicto armado entre el Gobierno y las Farc. En este debate, los voceros del "No" pusieron sobre la mesa su reclamo de lograr una justicia más retributiva, con un sistema de privación de la libertad efectiva que afectaría, entre otras cosas, el acuerdo en materia de justicia restaurativa. Tras un periodo de consultas y renegociación del acuerdo que incorporó algunas de las propuestas de la campaña del "No", se llegó a un nuevo acuerdo que fue suscrito el día 24 de noviembre de 2016 en la ciudad de Bogotá. Dicho acuerdo fue refrendado por el Congreso de la República el día 30 de noviembre de 2016. Por estar ante el momento histórico de la implementación de los acuerdos, se hace oportuno y pertinente evaluar el sistema de justicia restaurativa que contiene el acuerdo, con miras a un mejor entendimiento de su contenido, ventajas, limitaciones y problemas.

Este acuerdo plantea un Sistema Integral de Verdad, Justicia, Reparación y No Repetición (en adelante, el Sistema) bajo los objetivos de la satisfacción de los derechos de las víctimas, el establecimiento de responsabilidades de todos los participantes en el conflicto (directos o indirectos, combatientes o no combatientes), la no repetición para impedir nuevas formas de violencia y habilitar la convivencia y la reconciliación, y la seguridad jurídica y el debido proceso para sus participantes. Uno de los "paradigmas orientadores 
del componente de justicia" es la aplicación de una justicia restaurativa, "que preferentemente busca la restauración del daño causado y la reparación de las víctimas afectadas por el conflicto, especialmente para acabar la situación de exclusión social que les haya provocado la victimización" (p. 144). La justicia restaurativa atiende prioritariamente las necesidades y la dignidad de las víctimas y se aplica con un enfoque integral que garantiza la justicia, la verdad y la no repetición de lo ocurrido. Con dichos objetivos, el Sistema está compuesto por mecanismos judiciales y extra judiciales que se pueden resumir en la siguiente tabla 1.

El acuerdo sobre justicia dentro del punto de víctimas logrado en las conversaciones de La Habana establece que el Sistema es de carácter integral; por ende, tanto las medidas judiciales como las extrajudiciales tienen objetivos comunes que deben ser articulados en su implementación. En ese sentido, para alcanzar los objetivos de Verdad, Justicia, Reparación y No Repetición, los acuerdos hacen "especial énfasis" en medidas restaurativas y reparadoras para buscar reparar el sufrimiento y daño infligidos por las violaciones durante el conflicto y alcanzar justicia no solo con sanciones retributivas (punto 5.1). Así, se establece que las sanciones tendrán como "finalidad esencial satisfacer los derechos de las víctimas y consolidar la paz”, y deberán tener "la mayor función restaurativa y reparadora del daño causado, siempre en relación con el grado de reconocimiento de verdad y responsabilidad que se haga ante el componente de Justicia" (punto 60).

No obstante tener un fin común, se establecen diferentes funciones de las medidas a tomar con base en varios regímenes de responsabilidad que comprenden los siguientes cuatro posibles escenarios: la ausencia de responsabilidad, la sanción alternativa con medidas reparadoras y restauradoras, la sanción 'alternativa' con penas de privación efectiva de libertad rebajadas pero retributivas, y sanciones ordinarias que oscilan entre los 15 y los 20 años de privación efectiva de libertad. Estos regímenes dependen de cinco grandes escenarios de responsabilidad aplicables a quienes serán procesados por el Sistema, así:

i) Quienes no tendrán responsabilidad por criterios de selección de gravedad de las violaciones que cometieron o por ser beneficiados con amnistías; ii) quienes reconozcan verdad y responsabilidad ante la Sala de Reconocimiento, respecto a determinadas infracciones muy graves, tendrán una responsabilidad de sanciones con funciones reparadoras y restauradoras que oscilarán entre cinco años y ocho años, con posibilidad de restricciones efectivas de la libertad necesarias para asegurar el cumplimiento de la sanción, "condiciones que en ningún caso se entenderán como cárcel o prisión ni adopción de medidas de aseguramiento equivalentes" (punto 60); iii) quienes reconozcan tardíamente, ante la sección de enjuiciamiento y antes de la sentencia, serán condenados a sanciones reducidas 'alternativas' de pena privativa de la libertad de 5 a 8 años que "tendrán una función esencialmente retributiva"; iv) para quienes 


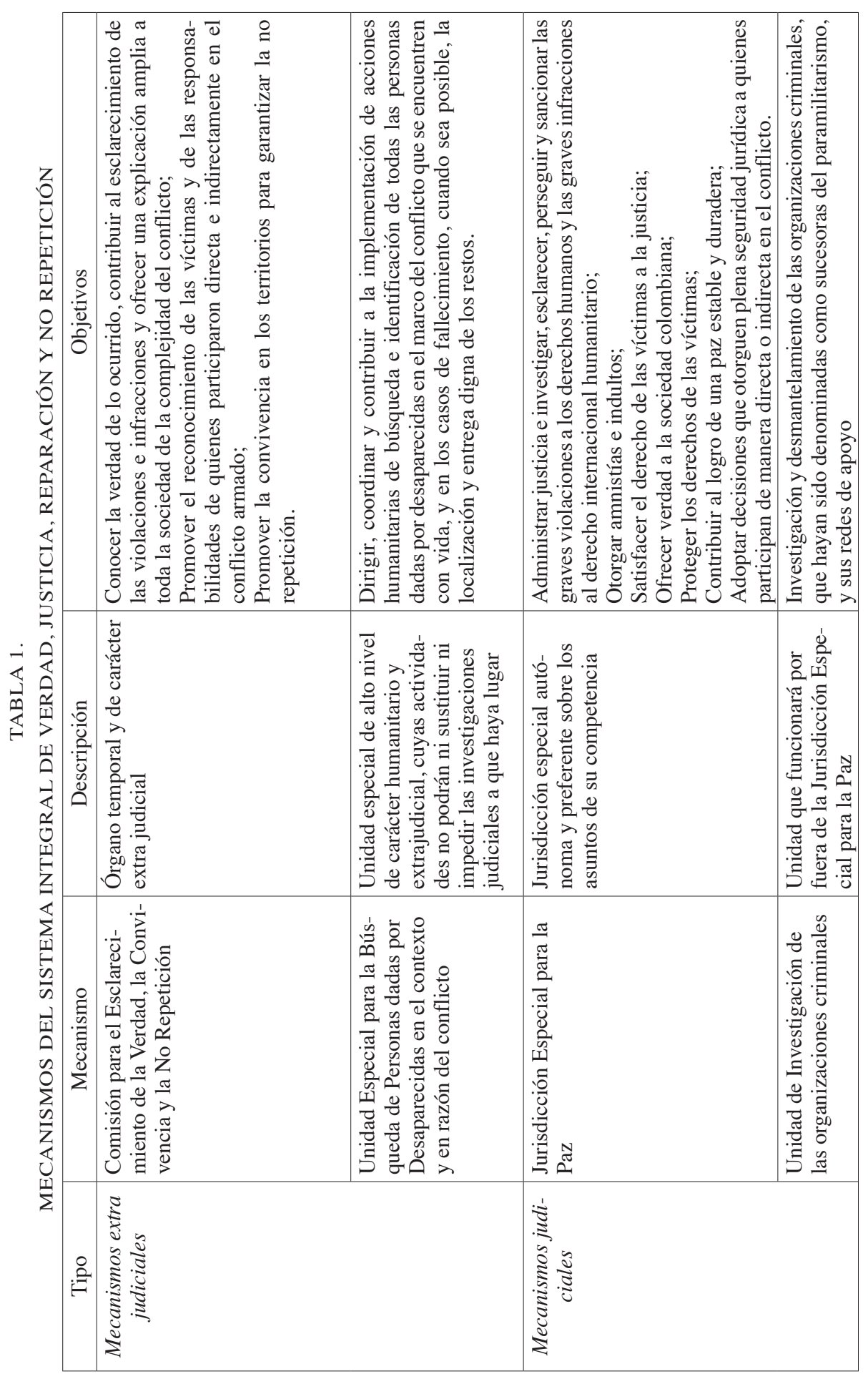


no hayan tenido una participación determinante en las conductas más graves y representativas, aun interviniendo en ellas, se pueden conceder sanciones de dos a cinco años; v) se podrán imponer sanciones ordinarias cuando no exista reconocimiento de verdad y responsabilidad bajo las funciones previstas en las normas penales, con privación efectiva de libertad de entre 15 y 20 años en el caso de conductas muy graves.

Nuestro propósito en este estudio es entender el alcance de las disposiciones restaurativas que parecen estar reducidas al segundo escenario del anterior esquema; esto es, para quienes reconozcan verdad exhaustiva, detallada y plena en la Sala de Reconocimiento de Verdad y Responsabilidades. Para estas personas se estableció que ante la mencionada instancia podrá presentarse un "proyecto detallado, individual o colectivo, de ejecución de los trabajos, obras o actividades reparadoras y restaurativas", que podrá incluir una serie de trabajos, obras y actividades que son determinados en el acuerdo bajo la forma de un listado de sanciones a implementar según su lugar de materialización, bien en zonas rurales ${ }^{1}$ o urbanas $^{2}$, o según se trate de limpieza y erradicación de restos explosivos de guerra, municiones sin explotar y minas antipersonal de las áreas del territorio nacional que hubiesen sido afectadas por estos artefactos, sin importar de su ubicación concreta (punto 75).

Tras esta breve descripción y ubicación del componente de justicia restaurativa en los acuerdos de La Habana, nos adentraremos en discutir: ¿ es el Sistema Integral de Verdad, Justicia, Reparación y No Repetición un acuerdo de justicia restaurativa? Con este objetivo haremos primero una delimitación conceptual de la justicia restaurativa desde una perspectiva criminológica, para luego regresar al acuerdo y hacer un examen de la aptitud, posibilidades y contradicciones del mismo frente a la justicia restaurativa.

1 La enumeración de medidas para las zonas rurales es: "1. Participación/Ejecución en programas de reparación efectiva para los campesinos desplazados. 2. Participación/Ejecución de programas de protección medioambiental de zonas de reserva. 3. Participación/Ejecución de programas de construcción y reparación de infraestructuras en zonas rurales: escuelas, carreteras, centros de salud, viviendas, centros comunitarios, infraestructuras de municipios, etc. 4. Participación/Ejecución de programas de desarrollo rural. 5. Participación/Ejecución de programas de eliminación de residuos en las zonas necesitadas de ello. 6. Participación/Ejecución de programas de mejora de la electrificación y conectividad en comunicaciones de las zonas agrícolas. 7. Participación/Ejecución en programas de sustitución de cultivos de uso ilícito. 8. Participación/ Ejecución en programas de recuperación ambiental de las áreas afectadas por cultivos de uso ilícito. 9. Participación/Ejecución de programas de construcción y mejora de las infraestructuras viales necesarias para la comercialización de productos agrícolas de zonas de sustitución de cultivos de uso ilícito" (punto 75).

2 La enumeración de medidas para las zonas urbanas es: "1. Participación/Ejecución de programas de construcción y reparación de infraestructuras en zonas urbanas: escuelas, vías públicas, centros de salud, viviendas, centros comunitarios, infraestructuras de municipios, etc. 2. Participación/Ejecución de programas de desarrollo urbano. 3. Participación/Ejecución de programas de acceso a agua potable y construcción de redes y sistemas de saneamiento" (punto 75). 


\section{JUSTICIA RESTAURATIVA: UNA DISCUSIÓN CONCEPTUAL}

Es difícil precisar cuándo se dio el "nacimiento" de la justicia restaurativa, sobre todo teniendo en cuenta que ella propone la utilización de algunas prácticas que pueden ser consideradas como ancestrales en nuestras sociedades. Los sistemas de atribución de responsabilidad en los cuales los participantes se organizan en círculos para atribuir una solución o consecuencia a la situación problemática son una práctica recurrente en diversas poblaciones originarias del continente americano y del mundo. Sin embargo, en décadas recientes la justicia restaurativa ha sido sistematizada como un modelo alternativo de justicia, o, más precisamente, un modelo alternativo de gestión de conflictos. Desde ese momento, al cual le advino una particular difusión mundial, la justicia restaurativa se ha presentado en una forma de paralelismo con los mecanismos tradicionales penales y ha sido motivo de diferentes debates sobre su conceptualización.

Así, aunque la justicia restaurativa trae consigo la recuperación de ideas ancestrales sobre la composición de conflictos, no siendo posible, por tanto, indicar su autoría y un momento particular de su creación, es relevante destacar el liderazgo de Howard Zehr en este campo. Considerado como uno de los autores más importantes en el tema, se estima que fue él quien más contribuyó a la sistematización de la justicia restaurativa como modelo de justicia y a su difusión internacional. En cuanto a las (in)definiciones de la justicia restaurativa, Zehr argumenta:

¿Cómo, entonces, se debe definir justicia restaurativa? Aunque exista una comprensión general sobre sus contornos básicos, los profesionales del tema no han logrado un consenso en cuanto a su significado específico. Algunos de nosotros cuestionamos la utilidad de una definición, o incluso dudamos de la prudencia de ceñirse a una definición particular. Si bien se reconoce la necesidad de tener principios y criterios aptos, nos preocupa la soberbia y el propósito de establecer una conceptualización rígida (Zehr, 2012: 48, trad. libre).

Para algunos teóricos del modelo, la falta de un concepto único para la justicia restaurativa es en sí una característica de ella. La tentativa de circunscribirla a un cierto concepto estaría en contra de lo que ella misma defiende, ya que la justicia restaurativa propone un cuadro teórico y filosófico alternativo al del derecho tradicional, que busca un continuo desarrollo de su contenido, y en esta búsqueda no puede darse primacía a una cierta definición sobre las otras. Por el contrario, otros piensan que se debería poder definir el modelo restaurativo. El hecho de tener una definición del modelo, argumentan, tiene una incidencia directa sobre las prácticas, por lo que una buena conceptualización aumentaría su potencial transformador. 
Por lo pronto, este artículo, más que adoptar una u otra posición, busca visualizar la falta de consenso conceptual y cómo esto hace parte de la dinámica propia del campo que se ha conformado en torno a este modelo alternativo de gestión de conflictos. Por lo pronto vamos a tomar los debates alrededor de su conceptualización, entendiéndolos como factores que dinamizan su campo teórico y práctico. No obstante, también debemos afirmar que las imprecisiones teóricas en relación con la justicia restaurativa tienen impactos notables en las prácticas relacionadas con el modelo, debilitándola en varios niveles. Entre estos, en lo relativo a su campo de acción, el hecho de que un gran número de acciones puedan ser consideradas como de justicia restaurativa atenúa su fuerza crítica y su distintividad al interior de la justicia penal tradicional.

En efecto, el hecho de que en el nivel práctico casi todo pueda ser justicia restaurativa hace que su campo sea realmente indeterminado, haciendo que los actores que la operan generen una especie de competición sobre las definiciones de los contenidos correctos o deseables. Por otra parte, en un nivel teórico, algunas definiciones pueden limitar la potencialidad crítica del modelo haciendo que en últimas acabe por reforzar el sistema de justicia penal con el cual teóricamente compite.

Esta última idea la explicaremos estudiando dos formas de conceptualización limitadoras del espectro crítico de la justicia restaurativa que pueden detectarse tanto en las definiciones por oposición con la justicia retributiva como en aquellas definiciones negativas (por lo que no es). La primera de estas definiciones es a la que más recurren los teóricos ${ }^{3}$, y establece una oposición entre la justicia restaurativa y la justicia retributiva. Un ejemplo de esta definición puede resumirse en un esquema como el propuesto a continuación.

TABLA 2 .

JUSTICIA RESTAURATIVA/JUSTICIA RETRIBUTIVA

\begin{tabular}{|l|l|}
\hline \multicolumn{1}{|c|}{ Justicia tradicional } & \multicolumn{1}{c|}{ Justicia restaurativa } \\
\hline Crimen definido como violación a una regla. & $\begin{array}{l}\text { Crimen definido por la afectación a las personas } \\
\text { y a las relaciones. }\end{array}$ \\
\hline Daño definido en abstracto. & Daño definido en concreto. \\
\hline $\begin{array}{l}\text { Crimen visto como categóricamente diferente } \\
\text { de otros daños. }\end{array}$ & $\begin{array}{l}\text { Crimen reconocido como relacionado a otros } \\
\text { daños y conflictos. }\end{array}$ \\
\hline El Estado es visto como víctima. & Las personas y las relaciones son las víctimas. \\
\hline $\begin{array}{l}\text { Estado y ofensor son vistos como partes } \\
\text { primarias. }\end{array}$ & $\begin{array}{l}\text { Víctima y ofensor son vistos como partes } \\
\text { primarias. }\end{array}$ \\
\hline $\begin{array}{l}\text { Necesidades y derechos de las víctimas son } \\
\text { ignorados. }\end{array}$ & $\begin{array}{l}\text { Necesidades y derechos de las víctimas son } \\
\text { centrales. }\end{array}$ \\
\hline Dimensiones interpersonales son irrelevantes. & Dimensiones interpersonales son centrales. \\
\hline
\end{tabular}

3 Ejemplos de este tipo de definición en Zehr (1990, 271), Melo, EdnIR y YAZbeK (2008, 192) y ARIAS et al. $(2011,8)$. 


\begin{tabular}{|l|l|}
\hline \multicolumn{1}{|c|}{ Justicia tradicional } & \multicolumn{1}{c|}{ Justicia restaurativa } \\
\hline $\begin{array}{l}\text { La naturaleza conflictiva del crimen es obs- } \\
\text { curecida. }\end{array}$ & $\begin{array}{l}\text { La naturaleza conflictiva del crimen es re- } \\
\text { conocida. }\end{array}$ \\
\hline Afectaciones del ofensor son periféricas. & Afectaciones del ofensor son importantes. \\
\hline Ofensa definida en términos técnico-jurídicos. & $\begin{array}{l}\text { Ofensa entendida en un contexto amplio: } \\
\text { moral, social, económico y político. }\end{array}$ \\
\hline
\end{tabular}

Fuente: Melo, Ednir y Yazbek (2008, 192).

Respecto a las definiciones negativas (por lo que no es) de la justicia restaurativa podríamos referirnos a aquella intentada por Zehr (2012) en los siguientes términos:

La JR no tiene como objeto principal el perdón o la reconciliación; la JR no es mediación; la JR no tiene por objetivo principal reducir la reincidencia o las ofensas en serie; la JR no es un programa o un proyecto específico; la JR no fue concebida para ser aplicada a las ofensas comparativamente menores o a ofensores primarios; la JR no es algo nuevo ni originado en Estados Unidos; la JR no es una panacea ni necesariamente un sustituto para un proceso penal; la JR no es necesariamente una alternativa a la prisión; la JR no se contrapone necesariamente a la justicia retributiva (Zehr, 2012: 18, trad. libre).

Estas definiciones las hemos categorizado como limitadoras del espectro crítico de la justicia restaurativa en tanto, por estar construidas en contraste con las ideas de justicia retributiva y en general con la justicia penal, acaban por reforzar la centralidad de ese sistema como referente, colaborando para la conservación de la marginalidad de la justicia restaurativa. En otras palabras, el alcance crítico de la justicia restaurativa permanecerá limitado si continuamos pensándolo a partir del molde del modelo de justicia penal (Tonche, 2016).

Tomando esto en consideración, y a pesar de las dificultades descritas al intentar definir la justicia restaurativa, es posible decir que su noción se refiere básicamente a un modelo alternativo de administración de los conflictos cuyo objetivo es reparar los daños y restaurar las relaciones afectadas por un conflicto concreto. A diferencia de lo que el modelo de justicia común hace, centrándose en el acto intencional y en su punición, nos referimos aquí a la restauración de las personas y los daños que emergen de una cierta situación problemática. Esta es considerada como su principal novedad, porque busca un desplazamiento de la atención de la justicia penal al daño causado a la víctima y a la sociedad. Grosso modo: lo más importante de este modelo es restaurar, no punir ${ }^{4}$.

4 No obstante, por ejemplo, el Manual sobre programas de justicia restaurativa de la Oficina de las Naciones Unidas contra la Droga y el Delito usa una definición que no exige un tal divorcio 
Cabe destacar que la utilización en este escrito del término administración o gestión de conflictos es intencional y diverge de la noción ordinaria utilizada en la literatura, que usualmente entiende la justicia restaurativa como un 'modelo alternativo de resolución de conflictos'. La expresión escogida se debe a que mientras hablar de "resolución" presupone el fin o la solución del conflicto, entendemos que esto no es siempre logrado o muchas veces ni siquiera deseado por las partes en disputa. No pocas veces quien es perjudicado por una situación conflictiva busca simplemente un reconocimiento de su demanda, de su estatus de víctima o simplemente de que un acto indebido aconteció.

Para alcanzar sus objetivos de restauración de los lazos sociales afectados, la justicia restaurativa propone formas más consensuales de tratamiento del conflicto, por medio de las cuales las partes pueden manifestarse en pie de igualdad, contando para ello con la ayuda de un tercero imparcial, cuyo papel en el proceso reside en facilitar el diálogo y no en juzgar como normalmente acontece en el sistema de justicia oficial. Este facilitador de justicia no precisa tener formación en derecho, pero es necesario que tenga una cierta capacitación para ejercer esta función.

Salimos así de un modelo tripartito (justicia común) para pasar a un sistema circular (restaurativo); o sea, allí donde la justicia común propone una participación jerarquizada, la justicia restaurativa establece un propósito de horizontalidad de las relaciones que puede ser entendido como circular:

Justicia común

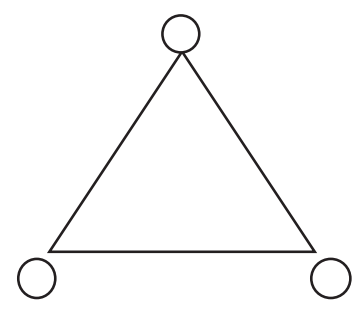

Justicia restaurativa
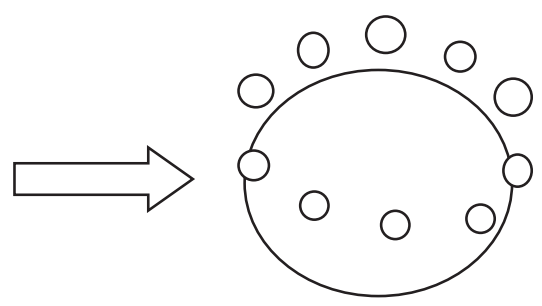

Bajo este esquema, existen diversas posibilidades de organización de los procedimientos restaurativos de gestión de conflictos. Hoy en día existen procedimientos como los círculos decisorios, los círculos de pacificación, la mediación víctima-infractor y las conferencias familiares. Otro modelo, tal vez el más difundido, es el de los círculos restaurativos, utilizados en 
países como Brasil. En los diferentes círculos, el propósito de ubicar a los participantes en forma de círculo busca situarlos en una misma posición, lo que de por sí intenta romper con las jerarquías y demás formalidades habituales de los ritos judiciales. Además de esto, el formato circular explicita los orígenes de la justicia restaurativa, centrados en la recuperación de las tradiciones en que los pueblos originarios o autóctonos resuelven sus conflictos. En países como Canadá y Nueva Zelanda, pioneros en la utilización del modelo restaurativo, la aplicación de la justicia restaurativa está fuertemente ligada a las tradiciones de sus pueblos originarios. En estos países la justicia restaurativa es empleada para atender casos considerados como graves, diferente a lo que sucede en países como Brasil o Colombia, en su derecho procesal ordinario, que enfocan su aplicación en casos considerados de bajo potencial ofensivo ${ }^{5}$.

Otro ejemplo importante de aplicación de la justicia restaurativa para casos graves puede ser encontrado en Sudáfrica. Allí fue implementado el modelo Zwelethemba, además de la Comisión de la Verdad que fue reconocida mundialmente como un mecanismo transicional aplicado para atender las atrocidades cometidas en el apartheid. Los mecanismos transicionales sudafricanos no instauraron una amnistía general que impusiese el olvido del antiguo régimen, sino que enfatizaron en la verdad y la responsabilización de los actores del conflicto, en lugar de hacerlo en la mera punición, que quedó en un segundo plano para favorecer la restauración social, en consonancia con una propuesta de justicia restaurativa (Pinto, 2007). Sin embargo, como lo resaltan Uprimny y Saffon (2005: 219), el caso sudafricano generó diferentes críticas frente a la utilización de la justicia restaurativa en el proceso de transición (Crocker, 2002; Wilson, 2002; Hamber, 2003); mientras que otros, a partir de este caso, han defendido la utilización de la justicia restaurativa para contextos de transición (Minow, 1998; Tutu, 1999).

El caso sudafricano puede darnos importantes pistas para pensar en la viabilidad de la utilización de principios restaurativos para el caso particular colombiano. En Colombia, la Constitución Política incluyó a partir del año 2002 una disposición según la cual la ley debe fijar los términos en que podrán intervenir las víctimas en el proceso penal y los mecanismos de justicia restaurativa (art. 250, modificado por el Acto Legislativo 3 de 2002). En este tenor, la Ley 1098 de 2006, por la cual se expide el nuevo Código de la Infancia y la Adolescencia, consagra que la finalidad del sistema de responsabilidad penal para adolescentes busca "garantizar la justicia restaurativa, la verdad y la reparación". A su vez, el Libro vi del Código de Procedimiento Penal se dedica a la justicia restaurativa: en su Capítulo I define los programas de justicia restaurativa como "todo proceso en el que la víctima y el imputado, acusado

5 Sobre una problematización del concepto de conflictos de 'menor potencial ofensivo' ver Fuluin (2011), AZEvedo (2001) y SinHORETTO (2011). 
o sentenciado participan conjuntamente y de forma activa en la resolución de cuestiones derivadas del delito en busca de un resultado restaurativo, con o sin la participación de un facilitador" (art. 518 CPP). El resultado restaurativo se identifica en la ley como el "acuerdo encaminado a atender las necesidades y responsabilidades individuales y colectivas de las partes y a lograr la reintegración de la víctima y del infractor en la comunidad en busca de la reparación, la restitución y el servicio a la comunidad" (art. 518 CPP), que debe contener obligaciones razonables y proporcionadas con el daño ocasionado con el delito (art. 519 cPP). En este sentido, establece que son mecanismos de justicia restaurativa (art. 521 CPP): la conciliación preprocesal en los delitos querellables (art. 522 CPP), la conciliación en el incidente de reparación integral y la mediación para los delitos cuyo mínimo de pena no exceda de cinco años de prisión, siempre y cuando el bien jurídico protegido no sobrepase la órbita personal del perjudicado, y para los delitos con pena superior a cinco años con el fin de otorgar algunos beneficios durante el trámite de la actuación, o relacionados con la dosificación de la pena, o el purgamiento de la sanción (art. 523 CPP). En el contexto actual de las negociaciones de La Habana, esto presenta un nuevo desafío: habiendo confinado la justicia restaurativa principalmente a casos de menor potencial ofensivo, como lo muestra la regulación procesal penal en la materia, en el punto 5 del acuerdo de La Habana se presencia un eventual cambio de paradigma, favoreciendo su utilización para las más graves ofensas.

$\mathrm{Al}$ respecto debemos aclarar que, conceptualmente, restringir el uso de la justicia restaurativa a casos de menor potencial ofensivo puede ser entendido como un desperdicio, toda vez que se estaría limitando a casos donde, justamente, la necesidad de reintegración social es menor.

Si entendemos que el objetivo principal de la justicia restaurativa, al contrario que en el caso del sistema de justicia corriente, es reparar las relaciones afectadas por el conflicto y no la punición, es importante destacar de su alcance tres factores: primero, la reparación puede extenderse más allá de las dos partes en disputa, cobijando a toda persona o colectividad que pueda haber sido afectada; segundo, el resarcimiento no siempre debe ser material, puede ser moral, según la situación y el consenso entre las partes; tercero, es necesario resaltar que todos los participantes, participando de manera voluntaria en el proceso, tienen por ello normalmente un nivel de compromiso diferente con sus resultados.

Cabe destacar también que en el procedimiento restaurativo, además de que términos utilizados convencionalmente por la justicia ordinaria, como víctima, victimario o infractor, pueden ser entendidos como términos estigmatizantes, la justicia restaurativa presta atención al contexto en que se produjo el conflicto, siendo consciente de la posibilidad de que el agresor pueda también ser víctima o, incluso, lo contrario. 
Además de la presencia de las dos partes en conflicto y del facilitador, más personas pueden participar activamente en los procesos de justicia restaurativa (la familia o la comunidad, por ejemplo). De esta forma, al contrario de lo que hace el modelo de justicia común, que generalmente relega a la víctima a un segundo plano, la justicia restaurativa le concede un papel activo, al igual que a la comunidad afectada, sin desentenderse en todo caso de las necesidades del ofensor.

Aquí hablamos, por tanto, de una especie de reapropiación del conflicto por las partes. En Conflicts as Property Nils Christie (1977) muestra cómo la criminología ha ampliado un proceso de especialización en la gestión de los conflictos criminales, los cuales son expropiados a las partes directamente involucradas en ellos. Estos conflictos se convierten así en propiedad de otros, especialmente de los operadores jurídicos, que convierten los problemas reales de personas concretas en problemas del sistema encarnados en roles abstractos: de un lado, una víctima que es una especie de zombi o no-entidad, y de otro lado, un infractor que es una especie de cosa. Un útil, mejor. De este modo, los conflictos de orden criminal se convierten en propiedad de los expertos, y su gestión se torna en una forma de disposición de medidas útiles para conservar los intereses de otras personas. En ello, por supuesto, las necesidades de las víctimas se disuelven y las medidas se concentran en las ofensas pasadas.

Frente a esto, otra característica importante de la justicia restaurativa es que, al contrario de lo que sucede en el sistema de justicia oficial, que se centra en el pasado, en algo que aconteció y que no puede ser totalmente reparado, ella se preocupa por el futuro, ya que su foco es la necesidad de todos los participantes del conflicto de hallar medidas más consensuales para el problema, que puedan proporcionar restauración (Melo, 2005).

Zehr (2008) habla de tres pilares de la justicia restaurativa: daño y necesidad; obligación, y compromiso. El primer aspecto procura recuperar lo que el daño significa para las personas, de modo que no se entienda como un acontecer abstracto sino como una afectación concreta con manifestaciones reales. Este autor sostiene que nuestro sistema jurídico perdió de vista esta noción cuando el Estado asumió el lugar de víctima del conflicto, la cual pasó a ser secundaria en el proceso. Esto nos lleva al segundo aspecto (obligación). Para que el ritual alternativo tenga lugar es necesario que el ofensor se responsabilice por el acto cometido. El acto de responsabilización que para el sistema de justicia ordinario origina la punición del autor, en la justicia restaurativa da paso y habilita el compromiso de la persona en la reparación de los daños (de una posición pasiva a una activa, que puede ser entendida de la mano con el tercer pilar: compromiso). Así, la justicia restaurativa privilegia formas consensuales, participativas e incluyentes de administración del conflicto, en un espacio en que se incentive el diálogo. Estos diferentes elementos son resumidos en una definición, 
por oposición con la justicia retributiva, por Xiomara Arias et al. (2011: 8) quienes establecen:

Distinto al enfoque que ofrece de la Justicia Penal Retributiva, que se pregunta primero qué ley se infringió, quién lo hizo y cómo se castigará al ofensor, la Justicia Restaurativa se pregunta: ¿Cuál fue el daño? ¿Qué es necesario para reparar ese daño causado? ¿Quién es el o la responsable de repararlo? Al mismo tiempo, involucra a la sociedad y a las personas indirectamente lesionadas con el actuar ilícito, con la finalidad de buscar soluciones duraderas con seguimiento que permita la verificación de acuerdos. La Justicia Penal Retributiva busca una responsabilidad pasiva, una imputación subjetiva y una pena. Mientras que la Justicia Restaurativa conlleva una responsabilidad activa, una confrontación con el hecho y la víctima, así como una reparación del daño y restauración de las relaciones.

Por último queremos llamar la atención sobre el hecho de que la justicia restaurativa, con principios como la atención del daño y las necesidades de los involucrados en el conflicto, así como la utilización de procesos incluyentes y cooperativos (Zehr, 2008; 2012: 47), tiene una intención de gestión del conflicto que se aproxima a las ideas de respuesta circular de Mary Parker Follett, según la cual "toda reacción es siempre reacción a una relación [...] Nunca reacciono a usted, sino a usted-y-a-mí; o, para ser más preciso, es yoy-usted reaccionando a usted-y-yo" (Follett, 1930: 62, trad. libre). Aunque la autora se refiere más al campo de la psicología y con el objetivo principal de referirse al debate entre objetivismo y subjetivismo, sus hallazgos encajan y dan fundamento especial al modelo restaurativo en tanto aboga por la conservación de las relaciones sociales, tomando en consideración los actores de una forma horizontal y siempre activa en los problemas y su gestión ${ }^{6}$.

\section{CONSIDERACIONES FINALES}

En esta parte intentaremos hacer una evaluación de las provisiones sobre justicia restaurativa existentes en los acuerdos de La Habana. Para entender posibles alcances, avances, desafíos, limitaciones y problemas de estas disposiciones tendremos en cuenta tanto el estudio descriptivo de los acuerdos (primera parte) como el desarrollo conceptual relativo a la justicia restaurativa (segunda parte).

Por lo tanto, a partir de lo expuesto hasta ahora, se puede inferir que la justicia restaurativa está contemplada en el acuerdo de La Habana, en los siguientes aspectos (que podemos identificar como positivos, en tanto preservan una inspiración e idea restaurativas): en primer lugar, podemos destacar que el acuerdo establece como uno de los "paradigmas orientadores 
del componente de justicia" la aplicación de una justicia restaurativa; con dicha orientación, el acuerdo establece una cierta distancia respecto de las ideas retributivas ("[e]l Sistema Integral hace especial énfasis en medidas restaurativas y reparadoras, y pretende alcanzar justicia no solo con sanciones retributivas" (p. 128)). En este contexto y con dicha herramienta se busca reconocer la complejidad del conflicto (p. 134) por medio de una lógica de restauración de las relaciones, según la cual se debe entender y abordar las necesidades de las víctimas así como las circunstancias problemáticas del ofensor, procurando atender integralmente dichas condiciones con miras a construir las relaciones sociales que no se desentienda de lo por venir. La observancia de estos principios permiten pensar que la justicia restaurativa es referida asimismo como un mecanismo garantizador de la no repetición, o sea, promover medios para evitar que las violencias se repitan ("una justicia restaurativa que preferentemente busca la restauración del daño causado y la reparación de las víctimas afectadas por el conflicto, especialmente para acabar la situación de exclusión social que les haya provocado la victimización" (p. 144)).

Entretanto, en el acuerdo la justicia restaurativa es abordada como una especie de moneda de cambio con respecto a la verdad y el reconocimiento de responsabilidad: el tratamiento restaurativo es más beneficioso para el infractor, por lo que es concedido según su grado de contribución a la justicia (p. 164). Esto no es per se incompatible con la idea de justicia restaurativa; sin embargo, por la manera como están dispuestos los acuerdos, esta forma de otorgamiento de la justicia restaurativa no establece una distancia frente a la justicia retributiva, sino esencialmente una excepción a la misma, en una lógica según la cual lo retributivo (severidad) es la regla y lo restaurativo (beneficios) su excepción. Esta condicionalidad de la presencia de la justicia restaurativa lleva a pensar que el empleo de la justicia restaurativa aquí no busca realmente sustituir e innovar el sistema tradicional de penalización de los delitos, sino más bien excepcionarlo.

De esta situación puede derivarse un problema particular frente a la noción de justicia restaurativa, en el sentido de que puede llevar a perder el enfoque en el conflicto y en su gestión y pasar a un enfoque punitivo: los participantes concentran su atención en las consecuencias penales y conforme con ello estratégicamente se acogen a una u otra forma de justicia. Por lo tanto, aunque la aplicación de la justicia restaurativa puede representar otras formas de respuesta a los conflictos que escapan de la lógica punitiva del sistema de justicia criminal, la forma por la cual se conseguiría la adherencia de los participantes en el proceso restaurativo sería sobre todo por las ventajas que representaría en términos de sanciones menos restrictivas.

En los acuerdos, también, al referirse a la restauración se otorga un papel central a las víctimas, lo que en la letra de los acuerdos busca "la restauración del daño causado y la reparación de las víctimas afectadas por el 
conflicto" (p. 144). La centralidad de las víctimas que ha sido reclamada en las negociaciones como una condición y objetivo político, ético y jurídico toma una relevancia discursiva especial en el establecimiento de las formas de responsabilidad, particularmente cuando se refiere el acuerdo a aquellas medidas restaurativas.

Las víctimas, en un contexto como el colombiano, han sufrido diferentes formas de victimización y revictimización. La masividad del fenómeno y la gravedad del mismo autorizan para pensar que la consideración de las necesidades de las víctimas es fundamental en este contexto y se adecua a una lógica restaurativa. La importancia dada a las víctimas es clave en este contexto y no está en discusión en este texto, pues lo entendemos como una forma de avance frente a lo que nuestro sistema legal occidental ofrece regularmente a las víctimas en el proceso. Sin embargo, creemos que al hacer una evaluación de justicia restaurativa (y en general de todo tipo de justicia) es pertinente, necesario y apropiado referirnos y cuestionar el papel del ofensor en este proceso.

Según el acuerdo, "[d]eberá repararse el daño causado y restaurarse cuando sea posible" (p. 127). En este sentido, el punto de concentración de la restauración es el daño y con él su afectado, y no las relaciones sociales y con él los actores de la situación problemática que ocasiona la intervención del sistema jurídico. En este sentido, existe una concentración en entender la responsabilidad del ofensor y no existe un espacio para visibilizar sus necesidades. Esto puede ir además en contravía de las garantías de no repetición que se busca habilitar a través de una forma de justica restauradora según el acuerdo. Por ejemplo, si un victimario cometió diferentes violaciones por ausencia de oportunidades de vida, por una situación de un contexto de violencia y desintegración social, ¿cómo podemos garantizar que esta persona no repita la violencia si no se entiende y atiende a dichas necesidades? La justicia restaurativa, al ofrecer una consideración de los factores, actores y dinámicas presentes en las violaciones, no pretende crear una dinámica justificativa de las violaciones, ni negar su gravedad, responsabilidad o dimensión, sino que busca dar respuesta al conflicto (en lugar de dirigirse contra el ofensor) en un nivel de profundidad que la justicia retributiva no alcanza. Así, el objetivo sería sostener y enfatizar en la importancia de la víctima en el proceso de una forma que habilite una cierta horizontalidad en el proceso con el ofensor, de modo que, tal como lo formula la justicia restaurativa, se tome en consideración el conflicto en sí, lo que comprende también una referencia y espacio para las necesidades del ofensor. Ese es el nivel del desafío que plantea la justicia restaurativa a los abordajes tradicionales de la responsabilidad.

A nivel concreto, existe un sinnúmero de dudas, desafíos y problemas en la implementación de estas provisiones. Al hacer una revisión de los acuerdos se resalta que para los ofensores que sean objeto de medidas restaurativas (quienes reconozcan verdad exhaustiva, detallada y plena en la Sala de Reconocimiento de Verdad y Responsabilidades) existe un elenco de posibles medidas preestablecidas. Bajo un lenguaje de sanciones (lejano de la lógica 
de la justicia restaurativa), el acuerdo establece que los comparecientes ante la Sala de Reconocimiento de Verdad y Responsabilidad podrán presentar un proyecto de acciones reparadoras y restaurativas que "podrá incluir, entre otros, los siguientes trabajos, obras y actividades, los cuales no podrán ser incompatibles con las políticas públicas del Estado en la materia siempre que las anteriores sean acordes con las tradiciones y costumbres étnicas y culturales de las comunidades", estableciendo una distinción entre medidas a ser ejecutadas en zonas rurales y en zonas urbanas; así como permitiendo la participación en limpieza y erradicación de restos explosivos de guerra, municiones sin explotar y minas antipersonal de las áreas del territorio nacional que hubiesen sido afectadas por estos artefactos.

$\mathrm{Al}$ respecto, bajo unas ideas de justicia restaurativa es pertinente establecer que la existencia de un elenco de medidas en especie no se corresponde con una lógica restaurativa. Esta lógica debe permitir entender las especificidades de los conflictos, visualizar las necesidades de víctimas y de victimarios y dar una respuesta adecuada a través de medidas concretas. El hecho de establecer un catálogo de medidas en especie evade esta lógica, pues no pregunta siquiera por la situación problema de la que emerge la medida y congela una forma dialógica de construir las formas de gestión y las reparaciones debidas a las víctimas. La justicia restaurativa no se refiere a una concepción de penas en especie o condenas a trabajos, sino a una noción de medidas para la gestión de los conflictos sociales bajo una perspectiva constructiva que permita atender el hecho pasado pero que también garantice las relaciones sociales futuras.

¿Podrá la implementación de este acuerdo superar una lógica retributiva y lograr una auténtica restauración de la sociedad colombiana afectada por el conflicto armado? Sólo cuando podamos responder a esta pregunta podremos terminar este trabajo de reflexión sobre si el Sistema Integral de Verdad, Justicia, Reparación y No Repetición es un acuerdo de justicia restaurativa.

\section{REFERENCIAS}

Arias Madrigal, X. et al. (2011). Programa de Justicia Restaurativa en el Poder Judicial. San José: Costa Rica.

Christie, N. (1977). Conflicts as property. British Journal of Criminology, 17(1), 1-15.

Correctional Service Canada (2014). About Restorative Justice. Disponible en: http:// www.csc-scc.gc.ca/restorative-justice/003005-0007-eng.shtml

Follett, M. P. (1930). Creative experience. Longmans, Green and Co.

Gomes Pinto, R. S. (2005). Justicia restaurativa é possível no Brasil? En Slakmon, C.; De Vitto, R. y Gomes Pinto, R., orgs. Justicia Restaurativa. Brasília: Ministério da Justicia/PNUD. 
JACCOUd, M. (2005). Princípios, tendências e procedimentos que cercam a justiça restaurativa. En Slakmon, C.; De Vitto, R. y Gomes Pinto, R., orgs. Justicia restaurativa. Brasília: Ministério da Justicia/PNuD.

JACCOUD, M (2007). Innovations pénales et justice réparatrice, Champ pénal/Penal field. Séminaire Innovations Pénales. Disponible en: http://champpenal.revues.org/1269; OI:10.4000/champpenal.1269 [Consulta: 17 de junio de 2014].

JACCOUD, M. (1999). Les cercles de guérison et les cercles de sentence autochtones au Canada. Criminologie. Vol. 32, n. ${ }^{\circ}$ 1, primavera 1999, 7-105. Disponible en: http:// id.erudit.org/iderudit/004725ar

Melo, E. R.; Ednir, M. y Yazbek, V. C. (2008). Justicia restaurativa e comunitária en São Caetano do Sul: aprendendo com os conflictos a respeitar direitos e promover cidadania. Secretaria Especial dos Direitos Humanos da Presidência da República. Rio de Janeiro: CECIP.

Mesa de Conversaciones (2015). Comunicado Conjunto n. ${ }^{\circ}$ 64. La Habana, 15 de diciembre de 2015. Disponible en: [https://www.mesadeconversaciones.com.co/comunicados/ comunicado-conjunto-64-la-habana-15-de-diciembre-de-2015]

Pallamolla, R. DA P. (2009). Justicia restaurativa: da teoria à prática. São Paulo: IBCCRIM.

ONU, Resolución 12/2002 ONU. Disponible en: www.onu.org.br

Roche, D. (2007). Retribution and restorative justice. En Van Ness, D. W., ed. Handbook of restorative justice. Cullompton, UK; Portland, USA: Willan Publishing, 75-90.

Tonche, J. (2016). Justicia restaurativa e racionalidade penal moderna: una real inovación em matéria penal? Revista de Estudos Empíricos en Direito. Vol. 3, n. ${ }^{\circ} 1$.

Umaña, C. (2016). La mula muerta: el tema de la impunidad en Colombia y el contexto de las negociaciones en La Habana. Bogotá: Universidad Externado de Colombia, Serie Documentos de Trabajo, n. ${ }^{\circ}$ 58. Disponible en: [http://icrp.uexternado.edu.co/ working-papers/].

Umaña, C. y Pires, A. P. (2016). Derechos humanos y penas radicales: ¿crítica o justificación? La recepción del derecho internacional humanitario en el Código Penal colombiano. Oñati Socio-legal Series. Available from: HTTP://sSRn.COM/ABSTRACT=2627717

UPRIMnY, R. y SAFFon, M. P. (2005). Justicia transicional y justicia restaurativa: tensiones y complementariedades. En ANGELIKA RetTBERG, comp. Entre el perdón y el paredón: preguntas y dilemas de la justicia transicional. Bogotá: Universidad de los Andres, 211-232.

Zenr, H. (1990). Changing Lenses: A New Focus for Crime and Justice. Scottsdale, PA: Herald Press.

Zehr, H. (2012). Justicia restaurativa. São Paulo: Palas Athena (Trad. de The little book of restorative justice). 